\title{
Una política pública para el desarrollo del capital humano de funcionarios municipales: aprendizajes para el caso de la Academia de Capacitación Municipal y Regional
}

\author{
Edgar Rebolledo
}

Universidad de Chile

\section{Resumen}

Este estudio desarrolló un exhaustivo análisis de la experiencia internacional, a fin de dilucidar las distintas estrategias, abordadas por tres escuelas de formación de funcionarios públicos, en el desarrollo del capital humano dentro de la Administración Pública de sus respectivos países, y contrastar dicha experiencia con el caso chileno, dándole especial atención a la formación y capacitación de los funcionarios de gobiernos locales. Se propone que, a raíz de la nueva Ley, la institucionalidad de la Academia de Formación debe articular esfuerzos, recursos, actores y voluntades, a fin de que la formación y capacitación entregada por la Academia esté asociada al ascenso, aumento de grados y sean prioridad para el reclutamiento y selección, para cubrir cargos disponibles en las municipalidades que ingresen al sistema, tal como ocurre con las escuelas internacionales estudiadas.

Palabras clave: Capital Humano, Modernización del Estado, descentralización.

A public policy for the development of human capital of municipal officials: learning for the case of the Municipal and Regional Training Academy

\begin{abstract}
This study developed an exhaustive analysis of the international experience to elucidate the different strategies of three training schools for public servers in human capital development within the public service of their countries, and contrast that experience with the chilean case, giving special attention to the training of local government officials. It is proposed that, following the new law, the institutions of the "Academia de Formación" must coordinate efforts, resources, actors and wills, so the training provided by the Academy would be associated with the promotion, increasing of degrees and would be priority for recruitment and selection to cover positions available in municipalities entering the system, as in the case of the international schools studied.
\end{abstract}

Keywords: Human Capital, State modernization, decentralization.

*Dirección de correspondencia [Correspondence

address]: Edgar Rebolledo, Universidad de Chile

E-mail: edgarebolledo@gmail.com 


\section{Introducción}

Los municipios, por su cercanía o proximidad con la ciudadanía, se encuentran en una ubicación privilegiada, respecto de otros servicios del Estado, para detectar las necesidades y dar respuesta en forma rápida y oportuna a quienes más lo necesitan. Sin embargo, la mayoría de los municipios del país están lejos de cumplir con esta misión descentralizadora, toda vez que sus recursos financieros y humanos son insuficientes.

Lo anterior se explica por un inadecuado sistema financiero; una sobrecarga importante de tareas por parte del gobierno central; una demanda creciente por bienes y servicios públicos, no tan solo en cantidad sino que también de calidad, por parte de sus habitantes; y por problemas importantes de gestión (Asociación Chilena de Municipalidades, 2006; Horst, 2009).

Dichos problemas están fuertemente condicionados por las personas con las que cuenta cada municipalidad para llevar a cabo sus tareas y funciones, los funcionarios públicos; es decir, por su capital humano. Es por esto que, dado el nivel de gestiones que realiza la municipalidad, desde el punto de vista de la provisión de bienes públicos, un incremento de las capacidades y habilidades de los funcionarios para atender a las necesidades de la comunidad local, acarreará necesariamente un aumento del bienestar (Ormeño, 2011).

El nivel de profesionalización de los funcionarios municipales del país, según datos del SINIM 2012, alcanza solo a un 26,38\%; y el porcentaje del gasto municipal total, que se invierte en capacitación de sus recursos humanos, respecto del total de sus ingresos (descontando las transferencias) alcanza sólo $0,19 \%$; y el gasto en capacitación respecto del total de gasto en personal alcanza un 0,55\%.

A la luz de lo anterior, resulta importante preguntar ¿Qué rol le compete a la Academia de Capacitación Municipal y Regional en el desarrollo del capital humano de los funcionarios municipales?

De esta forma el objetivo de esta investigación fue conocer la situación actual de la formación de funcionarios públicos en otras escuelas o institutos a fin de obtener aprendizajes para la Academia de Capacitación Municipal y Regional.

\section{Gestión municial y capital humano}

El capital humano es definido por la Organización para la Cooperación y el Desarrollo Económico (OCDE) como "el conjunto de conocimientos, habilidades, competencias y atributos que le permiten a la gente contribuir a su bienestar personal y social, así como el de su país". Entendido de esta forma, según el Secretario General de la OCDE, Ángel Gurría, el capital humano juega un rol clave en el éxito económico de un país (Keeley, 2007).

Giménez (2005), establece que existen dos categorías de capital humano:

1. El capital humano innato: "distribuido entre los seres humanos por condiciones genéticas, las que provocan distintas aptitudes físicas e intelectuales".

2. El capital humano adquirido: referido a la educación formal e informal recibida y la experiencia acumulada.

A su vez, el capital humano adquirido se clasifica en dos categorías (Helpman y Grossman, 1993; Barro y Sala-i Martin, 1995; Lloyd-Ellis y Roberts, 2000):

1. Capital Humano Básico (KH): son los aprendizajes adquiridos que permiten a los trabajadores utilizar eficientemente el capital físico y las tecnologías de producción.

2. Capital Humano Calificado (KHC): se refiere al nivel de conocimientos que permiten alcanzar avances tecnológicos, innovación y desarrollo. Este está presente en los técnicos, profesionales e investigadores.

Así, sin stocks significativos de capital humano calificado, es imposible que los territorios puedan innovar y desarrollarse, toda vez que "la capacidad de adaptar tecnologías avanzadas puede tener un valor preponderante en los resultados de desempeño agregado, capacidad que está directamente ligada al desarrollo de las habilidades de capital humano" (Accioneli et al., 2007).

La formación del capital humano está determinada fundamentalmente por la educación y el acceso que las personas tienen a capacitación. Esto afecta aspectos no solo económicos e individuales, sino que también a nivel de país, afectando aspectos como el acceso a la salud, integración, perspectiva de empleo y en definitiva a la calidad de vida de la persona y la sociedad en su conjunto (Keeley, 2007).

Pese a todas las reformas tendientes a mejorar la gestión pública, en el ámbito del capital humano, el Estado chileno tiene mucho camino por recorrer, tanto para los funcionarios del nivel central en general, como para los funcionarios municipales en 
particular. Esto dado a que en el Estado, alrededor del $50 \%$ de los funcionarios se encuentran bajo condiciones laborales precarias, con un sistema de estatuto público laboral, que permite contratar a una persona a "contrata" sin concurso, por el plazo máximo de un año, renovable, pudiendo ser despedidos sin expresión de causa y sin indemnización en cualquier momento. En contraste, el otro porcentaje de funcionarios de planta goza de inamovilidad casi absoluta (ni de entrada, ni de salida, ni de ascenso), en promedio de bajo perfil técnico, y con un precario sistema de evaluación del desempeño. Generando por tanto, un sistema dual dentro del servicio público, con la coexistencia de mundos laborales completamente distintos (Waissbluth, 2006). Esto que ocurre a nivel central es replicado en el ámbito municipal, donde del total de funcionarios el $35 \%$ es de planta, el $14 \%$ es contrata y el $51 \%$ está contratado bajo la modalidad de honorarios (datos obtenidos de SINIM, 2012).

Un estudio desarrollado por SUBDERE en conjunto con la Universidad de la Frontera (2012) concluye que Chile es el país más centralizado de Latinoamérica. Además, los altos niveles de inequidad social se refuerzan y retroalimentan recíprocamente con la inequidad territorial, generando un espiral vicioso que constituye la principal marca de subdesarrollo.

La competitividad de una región es medida por el stock y la calidad de Capital Humano Calificado; por sus resultados económicos; la calidad de las empresas; la capacidad de innovación científica y tecnológica; infraestructura; sistema financiero; calidad de sus servicios públicos, municipios y gobiernos regionales; así como la diversidad de sus recursos naturales (SUBDERE- UFRO, 2012). En este sentido, las disparidades son extremas, donde la región metropolita tiene niveles de competitividad que en promedio, son cinco veces más altos que las regiones menos competitivas del país (Maule, O?Higgins, Araucanía) (SUBDERE- UFRO, 2012).

Un estudio de la OCDE (2009) señala que Santiago concentra el mayor stock de Capital Humano Calificado, la mayoría del capital político, económico e intelectual. Esto en definitiva, refuerza la concentración económica y genera desequilibrios regionales que persisten y se amplifican. En el marco de la globalización, esto resulta fatal, toda vez que esta implica un juego competitivo de alta complejidad, en cual solo sobreviven los más inteligentes, veloces, flexibles y complejos (Boisier, 2006).

La situación es preocupante al verificar que Chile no dispone de una política pública orientada a revertir las inequidades territoriales en general y en particular lo referido al capital humano calificado.
Según SUBDERE - UFRO (2012), se genera un círculo vicioso en la administración pública nacional, en el cual, dada la escasez de capital humano calificado, los gobiernos subnacionales presentan bajos niveles de gestión, lo que los calificara como no "confiables" para otorgarles nuevas funciones y atribuciones.

Según González, Lagos \& Zamorano (2010), citados por SUBDERE - UFRO (2012), la calidad de las políticas públicas y los servicios entregados a la ciudadanía se explica, en buena parte, por el nivel de profesionalización y capacidades de los funcionarios públicos. El estudio plantea que en el resultado del Índice de Desarrollo Humano "existe una relación estadísticamente significativa entre el número de profesionales y productividad, donde por cada funcionario profesional aumentaría en 0,002 puntos el IDH".

Dado el nivel de gestiones que realiza la municipalidad, desde el punto de vista de la provisión de bienes públicos, un incremento de las capacidades y habilidades de los funcionarios para atender a las necesidades de la comunidad local, acarreará necesariamente un aumento del bienestar (Ormeño, 2011). También, una mayor profesionalización podría incidir en cambios sustantivos en la gestión municipal, disminuyendo las sospechas teóricas respecto de sus bajos niveles de gestión que estarían impidiendo el traspaso de mayores competencias, funciones y recursos, y por tanto autonomía, para el logro de la deseada descentralización.

En lo que respecta a la posibilidad de que las municipalidades puedan manejar su dotación de personal y plantas municipales autónomamente, las últimas iniciativas modernizadoras se produjeron en la década de los noventa, mediante la Ley № 19.280 que modificó la Ley № 18.695 Orgánica Constitucional de Municipalidades y la Ley № 19.602, que entre otras materias, crea el cargo de Administrador Municipal. A pesar de esto, actualmente existe un número importante de municipios que no cuentan en sus plantas con los cargos que la propia Ley № 18.695 dispone .

En lo que se refiere a reformas administrativas vinculadas a gestión de personas en los municipios, un avance importante lo constituye la aprobación, el 21 de enero de 2014, por parte del Congreso Nacional, del Proyecto de Ley que perfecciona el rol fiscalizador del Concejo; Fortalece la Transparencia y Probidad en las municipalidades; crea cargos y modifica normas sobre personal y finanzas municipales (Boletín № 8210-06).

Aún no existe consenso respecto de la creación de 
un Sistema de Selección de Directivos Municipales o Alta Dirección Pública Municipal, con lo neurálgico que esto representa para la modernización del sistema municipal chileno.

Por otro lado, cabe destacar el importante avance que representa la creación del Fondo Concursable de Formación de Funcionarios Municipales. Esto porque constituye la primera señal de carácter legal, que va en directa relación con el desarrollo del capital humano de los funcionarios municipales. A su vez, el texto aprobado del proyecto considera la incorporación en el presupuesto municipal recursos destinados a financiar capacitación de los concejales en materias relacionadas con gestión municipal. Este avance legal podría favorecer directamente a la autorrealización y motivación de los funcionarios municipales, bajo la convicción de que no depende exclusivamente de las remuneraciones, sino que el hecho de tener el carácter de sujetos partícipes en programas y servicios que contribuyen a mejorar la calidad de vida de una sociedad local, de la cual ellos también forman parte (Bonardo, 2009).

Los Estudios de Necesidades de Capacitación Municipal años 2008 y 2012, y Estudios Diagnóstico Nacional de la Gestión Municipal años 2010 y 2013; son concluyentes en señalar, que un número muy acotado de los municipios cuentan con políticas de desarrollo de gestión de personas. Los datos permiten afirmar que no existe un despliegue importante del área de recursos humanos. Se observa escaso avance en cuanto a políticas y procesos; un bajo nivel de gestión de la capacitación; y un bajo nivel de preocupación por las materias relativas al bienestar y la seguridad en el trabajo.

La creación de la Dirección Nacional de Servicio Civil, ha sido un esfuerzo importante en materia de gestión de personas del sector público. Para ello creó el Modelo de Gestión de Personas para la Administración Central del Estado, el cual busca "la articulación de la visión; la investigación de la capacidad actual y futura; la conciencia de la brecha que separa las necesidades futuras y actuales; así como la creación de una estrategia de desarrollo de personas, elementos que se reajustan continuamente según los cambios en los objetivos organizacionales" (Abarzúa, 2012). Este modelo es el clásico modelo sistémico compuesto por las etapas de Detección de Necesidades de Capacitación, Planificación, Ejecución y Evaluación de la Capacitación (Abarzúa, 2012).

Se entiende por Detección de Necesidades de Capacitación el proceso de investigación que establece las carencias y deficiencias cuantificables o mesurables existentes en los conocimientos, habilidades y actitudes del trabajador y la norma o patrón de desempeño establecido como requerimiento del cargo. Así, pretende hacer más productiva una organización con la detección de sus necesidades ya que orientará para poder estructurar planes y programas que permitan satisfacer las necesidades de organización de forma clara y precisa, con el fin de llevarla al logro de sus objetivos (Abarzúa, 2012).

Por Planificación de la Capacitación (Diseño Instruccional) se entiende un proceso sistemático, planificado y estructurado, que se apoya en una orientación psicolaboral adecuada a las necesidades de aprendizaje de los trabajadores (Abarzúa, 2012).

Por último, la Evaluación de la Capacitación "es una estrategia necesaria para garantizar la calidad de las acciones formativas que se llevan a cabo en su seno y para impulsar el proceso de aprendizaje constante que el entorno actual exige" (Abarzúa, 2012).

Importante en la gestión de Capacitación al interior de las organizaciones del Sector Público es la conformación del Comité Bipartito de Capacitación, entendido como una "instancia de participación para asesorar a la administración de los Servicios Públicos en la orientación, priorización, programación y ejecución de las acciones de capacitación en beneficio de sus funcionarios" (Abarzúa, 2012). El Comité Bipartito de Capacitación debe estar constituidos en partes iguales por representantes de la dirección superior de la institución y por representantes de los funcionarios que se desempeñan en ella. El rol del Encargado de Capacitación, en esta instancia, es ser el especialista y referente técnico que debe orientar conceptual y metodológicamente al Comité Bipartito de Capacitación para el cumplimiento de sus responsabilidades.

\section{Metodología}

Para responder a la pregunta anteriormente planteada, esta investigación desarrolló un exhaustivo análisis de la experiencia internacional, a fin de dilucidar las estrategias de tres escuelas de formación de funcionarios públicos para desarrollar el capital humano de sus respectivas Administraciones Públicas.

La mayor fuente de información para esta investigación provino de la revisión bibliográfica de estudios académicos de las distintas escuelas o institutos de formación de funcionarios públicos, así como normativa aplicable, decretos, estatutos, memorias anuales, informes de gestión, comunicados de prensa, manuales de operación, lineamientos y otros documentos disponibles en los sitios web de 
los casos estudiados.

Cabe señalar que los 3 casos analizados, fueron seleccionados en virtud de su trayectoria, experiencia, por el grado de reconocimiento a nivel internacional y por ser tres casos distintos entre sí, permitiendo considerar distintos modelos. Por otro lado, estos casos también fueron seleccionados en virtud de la información relevante que ellos ponen a disposición en sus páginas web, facilitando la investigación.

\section{La experiencia internacional}

\section{El Instituto Nacional de Administra- ción Pública de España (INAP)}

\section{Perspectiva Institucional}

El Real Decreto 464/2011 del 1 de abril de 2011 del Ministerio de Política Territorial y Administración Pública, que aprueba los Estatutos y actual configuración y funciones del Instituto Nacional de Administración Pública de España (INAP), señala que este es un organismo público, dedicado a la selección, formación y perfeccionamiento de empleados públicos, así como a la realización de estudios y publicaciones en el ámbito de la Administración y de la Función Pública. En sus Estatutos se define como un organismo autónomo (de los previstos en la Ley 6/1997 de 14 de abril), con personalidad jurídica pública diferenciada, patrimonio y tesorería propios, así como autonomía de gestión.

Su régimen jurídico lo otorga la Ley 6/1997 de 14 de abril, que es la Ley de Organización y Funcionamiento de la Administración General del Estado; la Ley 47/2003 del 26 de noviembre Ley General Presupuestaria; y las demás disposiciones aplicables a los organismos autónomos vinculados a la Administración General del Estado. El Real Decreto $256 / 2012$ de 27 de enero de 2012 , establece que el INAP está inserto en el Ministerio de Hacienda y Administraciones Públicas de España, específicamente en la Dirección General de la Función Pública.

Los Estatutos del INAP establecen que los Órganos Rectores del mismo lo componen: El Consejo Rector y la Dirección.

\section{- El Consejo Rector:}

El Consejo Rector es un Órgano Colegiado de Dirección Estratégica y de Supervisión. Está compuesto por nueve miembros y es presidido por el Ministro de Hacienda y Administraciones Pública. Su función es conocer y aprobar las directrices generales; el plan anual de actividades; el anteproyecto de presupuesto; la liquidación presupuestaria; la memoria anual de gestión del INAP; los convenios de colaboración y cooperación suscritos; así como otras temáticas que se estime pertinente someter a su conocimiento y aprobación.

Está compuesto por los siguientes miembros: a) Presidente: Ministro de Hacienda y Administraciones Pública; b) Vicepresidente: la Secretaria de Estado para la Función Pública; c) Vocales: El Subsecretario del Ministerio de Hacienda y Administración Pública, El Director del Instituto Nacional de Administración Pública, El Director del Gabinete del Ministro de Hacienda y Administración Pública, El Secretario General Técnico de Hacienda y Administración Pública, Un representante propuesto por la Secretaría de Estado para la Función Pública, con rango de Director General y nombrado por el Presidente del Consejo Rector, y Tres representantes, con rango de Director o Subdirector General, competentes en las áreas de recursos humanos o formación, de los restantes departamentos ministeriales, quienes serán designados por el Presidente del Consejo Rector; y por último d) Secretario: El titular de la unidad con nivel orgánico de Subdirector General del Instituto Nacional de Administración Pública que designe su Director.

\section{- La Dirección:}

La Dirección del INAP, está compuesta de la siguiente estructura: a) El Director; b) La Gerencia; c) La Subdirección de Selección; d) Comisión Permanente de Selección; e) La Subdirección de Formación; f) La Subdirección de Programas Formativos en Administración Local; g) El Departamento de Publicaciones, Estudios y Documentación; y h) El Departamento de Relaciones Internacionales

En general a la Dirección y a los órganos que de ella dependen, le corresponde las funciones de dirección; coordinación; administración; representación; gestión financiera; contrataciones; ejecutar políticas de ingreso y formación; gestión de recursos humanos; nombramiento del profesorado; asesoría al ministerio respectivo en las materias del INAP; selección de los funcionarios de la administración del Estado; la formación y perfeccionamiento de los empleados públicos de la Administración General del Estado y de sus organismos públicos, así como del resto de entidades del sector público estatal, salvo en los supuestos en que otras disposiciones encomienden estas funciones a otros 
centros especializados; la realización de estudios e investigaciones multidisciplinares sobre las instituciones del Estado, de las Administraciones Públicas y de la función pública, así como la edición y publicación de las mismas; la concesión de becas y ayudas a empleados públicos de la Administración General del Estado y de sus organismos públicos, destinadas a estancias formativas en escuelas de administración pública e instituciones educativas extranjeras; la gestión y el mantenimiento de los servicios de biblioteca y documentación propios del Instituto, así como la conservación y acrecentamiento de su patrimonio bibliográfico; la participación en la definición de los perfiles de los directivos públicos y el asesoramiento técnico en el desarrollo de las políticas de directivos de las Administraciones Públicas; diseño y desarrollo de las actividades de formación o relacionales que impliquen una proyección en el exterior del Instituto y las derivadas de la cooperación internacional.

\section{Perspectiva Estratégica}

En un intento por sistematizar sus actividades, en el marco de un proceso de transformación, el INAP ha determinado su Plan Estratégico 20122015. En este consagra:

- La Misión "Crear conocimiento transformador en el sector público en beneficio de la sociedad, con el fin de propiciar la cohesión social y una democracia de alta calidad".

- La Visión "Ser la institución líder de las Administraciones Públicas españolas y referente internacional en la generación y difusión de conocimiento y aprendizaje transformadores, para promover una buena administración orientada al bien común".

- Objetivos Generales

1. Fortalecer el papel institucional del INAP en el ámbito nacional e internacional.

2. Generar conocimiento y reflexión de alta calidad para la toma de decisiones y el diseño de políticas públicas.

3. Vincular la formación y la selección a las necesidades reales de la Administración Pública, a las competencias profesionales de los empleados públicos y a la carrera profesional.

4. Convertir al INAP en el centro de excelencia en formación de directivos públicos.

5. Alinear la gestión del INAP con los retos estratégicos.

\section{Perspectiva de la oferta de capacitación para} capital humano de funcionarios municipales

Para efectos del desarrollo del capital humano municipal el INAP desarrolla una amplia oferta formativa y otras acciones como las que se señalan a continuación.

- Acciones formativas de ciclo largo (Dirigida principalmente a directivos y profesionales): Curso Superior de Estudios Territoriales y Urbanísticos; Curso Superior de Dirección Pública Local; Curso Superior de Dirección Económica Financiera; Curso Superior de Dirección de Recursos Humanos; Master en Dirección Pública.

- Red de Directivos Públicos: Esta Red busca facilitar el intercambio de información y experiencias profesionales. Cuenta con un Banco de Prácticas de Gestión de los Gobiernos Locales que puede ser consultada por todos aquellos que estén interesados en las mejoras de gestión.

- Banco de Prácticas de Gestión de Gobiernos Locales: Consistente en una Base de Datos, en la cual se incluyen los Planes de Mejora de gestión de los alumnos de los Cursos Superior de Dirección Pública Local y Superior de Dirección de Recursos Humanos del INAP que, por su originalidad, aplicabilidad práctica y su estructura sistemática, pueden constituir un referente para otras Administraciones Públicas.

- Itinerarios Formativos: Son un conjunto de acciones formativas que han sido elaboradas con el objetivo de proporcionar a los alumnos conocimientos especializados sobre una profesión o puesto de trabajo dentro de la Administración Local. Los destinatarios de este tipo de formación son los empleados públicos de cualquier ente local que requieran mejorar sus competencias en las distintas ocupaciones que propone el programa. Se dirigen fundamentalmente a trabajadores que ocupan puestos de responsabilidad en las materias propuestas.

- Acciones en colaboración: Son acciones destinadas a atender las necesidades formativas de los empleados locales dentro de las circunscripciones provinciales. Las necesidades son detectadas por las diputaciones provinciales, comunidades autónomas uniprovinciales, cabildos y consejos insulares. 


\section{Perspectivas docentes y métodos de en- señanza}

En el INAP, para cada formación en particular, se cran equipos docentes especializados de máximo prestigio académico, profesional y humano. Para esto, se determinan las actividades de formación requeridas; se efectúa una convocatoria con los planes de colaboración respectivos; se seleccionan los candidatos; y se contratan a los seleccionados como colaboradores docentes del INAP.

Cabe destacar que muchos de los profesores con que cuenta el Instituto, son funcionarios públicos en servicio activo. Estos se distribuyen en amplias áreas de conocimiento y poseen variadas destrezas. Es por esto que el Instituto dispone de mapas competenciales, que permiten ligar dichos dominios a la oferta formativa, dando de esta forma, mayor flexibilidad y uso a las cualificaciones de los docentes. De esta forma el INAP cuenta con una base de datos de profesorado interconectada con el catálogo formativo.

A fin de alcanzar un nivel de calidad alto y homogéneo para todas las acciones formativas es que en el INAP han establecido unas guías o métodos que orientan y apoyan el esfuerzo de los diseñadores, expertos, profesores y gestores que participan en los procesos de formación. Por otro lado, en el INAP desarrollan una completa metodología para la evaluación de la formación, a fin de medir la eficacia y la calidad de la formación ofertada.

\section{Perspectiva de la Investigación}

La investigación y la divulgación de la información relevada en materia de la Administración Pública, Instituciones del Estado, y función pública, con especial atención a las materias relacionadas con las materias de administración pública local, constituyen uno de los pilares fundamentales y estratégicos del quehacer del INAP.

Con este objetivo, el INAP tiene un Centro de Estudios el cual desarrolla: convocatorias permanentes para la contratación de proyectos de investigación; redes de investigación e innovación; Comunidad de Conocimiento Iberoamericano como espacio de aprendizaje e intercambio de experiencias de investigación; Observatorio de Buenas Prácticas en las Administraciones Públicas; Grupos de Investigación; el Grupo de Investigación sobre Administración Pública año 2032; Grupo de Investigación sobre Nuevos Modelos de Carrera Administrativa; Grupo de investigación sobre Central de Compras del Estado para productos Farmacéuticos; Beca de formación e investigación para titulados universi- tarios; Beca INAP-Fullbright de formación y perfeccionamiento profesional en los Estados Unidos; Becas de Promoción Interna del Ministerio de Hacienda y Administraciones Públicas para la preparación de pruebas selectivas de acceso por el sistema de promoción interna, a cuerpos y escalas adscritos al Departamento y cuya gestión se encomienda al INAP.

Además, INAP cuenta con una biblioteca, la que se ha constituido en un centro bibliográfico y documental especializado en Administración Pública y Derecho Público, llegando a ser referente y consulta obligada tanto en España como en el ámbito internacional.

\section{Perspectiva de Redes}

Resulta estratégico para el Instituto formar diversas alianzas con: los principales agentes de formación de funcionarios públicos; las Diputaciones Provinciales y la Federación Española de Municipios y Provincias (FEMP), para la formación y estudios locales; institutos y escuelas autonómicas de Administración Pública; otras Instituciones del Estado para desarrollar programas de formación conjunta; Escuelas e Institutos de formación de funcionarios públicos internacionales, tanto de Europa como de América Latina; así como con organismos internacionales y entidades dedicadas a las Administración Pública.

\section{Perspectiva de la Innovación}

Otro de los pilares fundamentales para las funciones y tareas que realiza el INAP es la innovación. Para ellos la Administración Pública debe asumir un rol ejemplar de liderazgo con respecto a la innovación, mejorando con esta la calidad de los servicios que se entregan a la ciudadanía. Por esto crearon INAP INNOVA, el cual busca incentivar el aprendizaje organizativo en los equipos humanos, crear conocimiento transformador, crear una conciencia innovadora en las Administraciones Públicas, y promover una buena Administración orientada al bien común.

Por otra parte, INAP también cuenta con lo que ha denominado Ecosistema Social y de Conocimiento, el que consiste en una herramienta segura e innovadora para que, tanto empleados públicos como la ciudadanía, puedan crear conocimiento transformador del sector público. Este ecosistema cuenta con tres herramientas: La Red Social Profesional; Banco de Conocimientos; y Banco de Innovación en las Administraciones Públicas. 
Finalmente, existen también incentivos y reconocimientos a la innovación en trabajos y tesis doctorales en materia de Administración Pública, tanto en el ámbito nacional como internacional. Por esto convoca anualmente premios a trabajos o tesis doctorales que generen conocimiento de calidad en este ámbito.

\section{Escuela Nacional de Administración de Francia (ENA)}

\section{Perspectiva Institucional}

La Escuela Nacional de Administración de Francia (ENA) fue creada por el General de Gaulle en 1945 bajo la Ordenanza N²5-2283 del 9 de octubre de ese mismo año. Es un Organismo Público de carácter administrativo, dotado de autonomía financiera, y se encuentra ubicado administrativamente bajo la tutela del Primer Ministro.

Las funciones para las cuales a ha sido creada son las siguientes: la formación inicial de altos funcionarios públicos franceses; la formación permanente de funcionarios franceses y el perfeccionamiento de funcionarios extranjeros que hayan recibido en sus países de origen una formación inicial completa y adquirido experiencia profesional; la cooperación europea e internacional, bilateral y multilateral, en materia de Administración Pública y política extrajera del gobierno francés; la investigación y la publicación en diferentes materias, especialmente en derecho y Administración Pública Comparada.

El Decreto N²002-49 del 12 enero de 2002, establece que los órganos rectores de la ENA lo componen el Consejo de Administración y la Dirección de la Escuela.

- El Consejo de Administración Es Presidido por el Vicepresidente de Consejo de Estado. Por su parte, tanto el Director General de la Administración y de la Función Pública; y el Secretario General del Ministerio de Relaciones Exteriores, son miembros por derecho propio. Además, este consejo lo componen siete miembros pertenecientes a la Administración Pública y que fueron formados en la ENA, los cuales son propuestos por el Ministro encargado de la Función Pública; Un ex alumno extranjero del Instituto Internacional de Administración Pública o de ciclos Internacionales de Formación permanente de la Escuela Nacional de Administración, el cual es nombrado a propuesta del Ministro de Relaciones Exteriores en conjunto con el Ministro de la Función Pública; Dos delegados de los alumnos franceses en formación, elegidos por cada promoción, y dos delegados de los alumnos extranjeros; Cinco personalidades elegidas a razón de sus competencias; Cuatro miembros nombrados a proposición de la federación de sindicatos de funcionarios públicos del Estado; Cuatro representantes elegidos del personal administrativo y de servicio de la Escuela.

Estos miembros son nombrados por cuatro años por Decreto, con posibilidad de reelección; se reúnen al menos tres veces al año, y todas las veces que su presidente los estime necesario, o a petición de al menos siete de sus miembros; dichos miembros ejercen sus funciones ad honorem, pudiendo reembolsar gastos.

En lo que respecta a sus funciones, este Consejo tiene la responsabilidad de aprobar el reglamento interno de la Escuela; ser consultado sobre el funcionamiento general, los medios y recursos financieros utilizados; aprueba la creación de filiales; aprobación de convenios; aprueba las condiciones de acceso a los regímenes de formación de la Escuela, así como las pruebas de admisión y ciclos preparatorios de concursos, etc.

- La Dirección de la Escuela

El Director de la Escuela es nombrado por Decreto por un período de cinco años renovables una vez. Son funciones del Director: la organización de los programas de estudio o formación; la disciplina interior y las sanciones respectivas; la ejecución de las medidas tomadas por el Consejo de Administración; representar a la Escuela ante la justicia y todos los demás actos de la vida civil; autorizar los ingresos y gastos de la Escuela; nombrar a todos los funcionarios que trabajan en la ENA; entre otras funciones.

Cabe señalar que tanto el Secretario General y los otros cuatro Directores son nombrados por el Primer Ministro y el Ministro de la Función Pública, a propuesta del Director de la Escuela.

Respecto del régimen financiero y contable, se puede señalar que la Escuela es regida por las leyes de carácter general aplicables a las instituciones de Administración Pública nacional.

Los ingresos de la Escuela provienen de: las Subvenciones del Estado, así como los aportes que puedan hacer toda persona pública o privada; Enajenación de bienes, fondos y valores; Ingresos de bienes fondos y valores; regalos y legados para el beneficio de la escuela; préstamos; venta de publicaciones; remuneración de las diferentes obras y servicios; reembolso de los estudiantes renunciados; los dividendos de filiales, cuando corresponda. Los gastos de la 
Escuela los componen los gastos de personal, gastos de operación y equipamiento, y todos los demás gastos necesarios para el normal funcionamiento de la escuela. (Decreto $\mathrm{N}^{\circ} 2002-49 \mathrm{del}$ 10 de enero de 2002)

\section{Perspectiva Estratégica}

Si bien la Escuela de Administración de Francia ENA no presenta manifiestamente un Plan Estratégico propiamente tal, señala que desde su fundación sus principios y visión han sido los de democratizar el acceso a la alta función pública y de profesionalizar la formación de los altos funcionarios de la Administración del Estado. Por lo tanto, declara que su Misión consiste en reclutar y entrenar a los hombres y mujeres que harán vivir y evolucionar a la Administración Pública, con pleno respeto de la ética del servicio público, y los valores de responsabilidad, neutralidad, y productividad. Sus principales funciones son: el reclutamiento y la formación inicial de los altos funcionarios públicos franceses y extranjeros; la formación continua y el perfeccionamiento de funcionarios franceses y extranjeros, bajo la modalidad de corta o larga duración; las relaciones europeas e internacionales bilaterales y multilaterales en materia de gobernanza pública y de administración; la formación en materias europeas y la preparación de concursos de acceso a las instituciones europeas.

\section{Perspectiva de la Oferta de Formación}

La oferta de formación y admisión de la ENA se clasifica en distintos programas que buscan acompañar al funcionario público en cada etapa de su carrera, es decir, desde su ingreso, su formación inicial, continua, o construidas a la medida de sus necesidades de capacitación. Por otro lado, la formación en la ENA implica intervención de los profesores desde el punto de vista teórico y práctico, con prácticas en terreno, estudios de caso, simulaciones y trabajos en grupo.

1. Formación Inicial por Concurso A este tipo de formación los alumnos solo ingresan a través de concurso, para lo cual es necesario aprobar pruebas rigurosas de selección. Anualmente son admitidos bajo esta modalidad un total aproximado de 80 alumnos franceses y una treintena de alumnos extranjeros seleccionados por el "Ciclo Internacional largo". Este tipo de formación, de dos años de duración, es de excelencia y reconocida internacionalmente, es la forma de reclutamiento y selección de los altos funcionarios públicos franceses. Este tipo de formación es alternado con períodos de estudios y prácticas tanto en el sector público como en el sector privado. El objetivo es entrenar a los alumnos a trabajar con un verdadero acercamiento a la realidad de la administración. De esta forma, durante sus estudios los alumnos realizan tres módulos: Europa, Territorios, Gestión y Gerencia Pública. Por otra parte, cabe señalar que dentro de estos módulos, la ENA forma a sus alumnos en una doble dimensión: La dimensión de la expetis técnica y la dimensión de la gerencia pública.

\section{Formación Continua}

- Programa de formación Este tipo de formación está dirigida a los directivos del sector público y privado, la cual considera once temáticas organizadas en tres ejes: 1) Desarrollo de Potencial Profesional; 2) Conocimiento del Entorno; y 3) Desarrollo de competencias sobre Europa. A este tipo de formación también pueden acceder altos directivos extranjeros.

Este programa de formación permite que las temáticas anteriormente señaladas se adapten a la medida de las necesidades y expectativas tanto del alumno como del organismo público o privado que solita la capacitación. Es decir, cada alumno o empleador, organiza las clases y temáticas de las cuales participará de acuerdo a sus necesidades. La forma de financiamiento de este programa formación, se efectúa por cada clase a la que asiste el alumno

- Ciclos de Formación de tipo reglamentario Dirigido a Administradores Civiles, Oficiales, Subprefectos y los Asistentes de Parlamentarios (de la Asamblea Nacional, del Senado y del Parlamento Europeo). Considera tres ciclos de formación: Ciclo Superior de Perfeccionamiento de Administradores (CSPA); Ciclo de integración de oficiales (CIO); Ciclo para asistentes de parlamentarios; Ciclo de Formación en Altos Estudios Europeos (CHEE)

Consiste en un seminario de alto nivel de 10 meses de duración, está dirigido a quienes ocupan altos cargos en una empresa, a altos funcionarios públicos, a funcionarios electos, periodistas, sindicalistas, miembros de instituciones internacionales o actores de la sociedad civil. Este programa busca familiarizar a los alumnos con los asuntos actuales de la política pública de la Unión Europea.

3. Masters Este tipo de programas está dirigido a Profesionales y alumnos de la Escuela. Los 
alumnos extranjeros inscritos en el Ciclo de Formación Inicial de la Escuela también pueden completar su formación con estos Masters. Existen tres masters: Master Europeo en Gobierno y Administración (MEGA), realizado en Alianza con la Universidad Paris 1 PantheonSorbone y la Universidad de Postdam (Alemania); Master en Gestión Pública (MGP), realizado en alianza con la Universidad Paris Dauphine; Master especializado en Prevención y Gestión Territorial de Riesgos (MPGTR),

4. Formación a medida La Escuela también ofrece formación a medida por cuenta de organismos públicos o privados, franceses o extranjeros. Tanto los contenidos, formatos y costos de cada curso son negociados entre la ENA y la entidad que solicita la capacitación. Las capacitaciones pueden ser de una jornada a dos meses, extensivas o intensivas, dentro de los dominios y competencias de la Escuela, estos ciclos de enseñanza pueden incluir visitas de estudios y prácticas. Se pueden ejecutar en reparticiones de la Escuela o en el lugar escogido por el cliente, en regiones o también en el extranjero.

\section{Perspectiva de la Investigación}

En lo que respecta a la Investigación, propiamente tal, se puede señalar que la Escuela cuenta con un Centro de Expertis y de Investigación Administrativa (CERA). Este Centro tiene por misión desarrollar las actividades de investigación en las áreas de Administración y políticas públicas, con una mirada tanto nacional como internacional. Entre sus principales tareas se encuentran: la edición de la Revista Francesa de Administración Pública (RFAP); organizar coloquios, mesas redondas y otras manifestaciones de carácter científico; desarrollar alianzas con otros establecimientos universitarios y centros de investigación enfocados en el estudio de la Administración Pública; representar a la Escuela en las redes internacionales en los dominios cubiertos por el Centro CERA.

Este centro está compuesto por su Director y dos investigadores, recibiendo además de manera regular a investigadores franceses o extranjeros. Participa además activamente del Polo Europeo de Administración Pública.

ENA también cuenta con un centro de documentación compuesto por conjunto de recursos documentarios que cuenta con 46 mil obras, más de 600 suscripciones a publicaciones periódicas y numerosos recursos en línea accesibles tanto física como a distancia, revistas especializadas, Etc. Este Centro cuenta con la acreditación del Centro de Documentación Europeo (CDE).

Por último, la ENA publica obras nacidas del trabajo de sus estudiantes y de investigaciones en el dominio de la Administración Pública. Por otra parte también publica la revista en línea y otras publicaciones de preparación a concursos de ingreso tanto a la Escuela como a otras instituciones europeas.

\section{Perspectiva de Redes}

La ENA forma parte de la cooperación y participación de redes de formación, investigación y desarrollo de la Administración Pública. En dicho sentido se puede señalar que tiene participación y presencia en África, Medio Oriente, América, Asia y Oceanía, Europa y en asuntos multilaterales.

La Escuela además realiza convenios, alianzas estratégicas y acciones de cooperación con un gran número de instituciones, gobiernos, escuelas y universidades orientadas a Administración Pública. Por mencionar algunas: la BundesAkademie für öffentliche Verwaltung (BaköV), Escuela de Administración Pública Alemana; el Instituto Nacional de Administración Pública de España (INAP); el Centro Nacional para la Administración Pública y Local de Grecia (EKDDA); la Escuela Nacional de Administración Pública de Varsovia (KSAP), entre otras.

\section{La Escuela Superior de Administra- ción Pública de Colombia (ESAP)}

\section{Perspectiva Institucional}

El Decreto $N^{\circ} 219$ del 27 de enero de 2004, establece que la Naturaleza de la Escuela Superior de Administración Pública, ESAP, creada por la Ley N¹9 de 1958, es un

"Establecimiento Público del orden nacional, de carácter universitario, adscrito al Departamento Administrativo de la Función Pública, del Ministerio de Hacienda y Crédito Público, dotado de personería jurídica, autonomía académica, administrativa y financiera, patrimonio independiente, de conformidad con las normas que regulan el sector educativo en general y el servicio público de la educación superior en particular, e integra el Sector Administrativo de la Función Pública". (DIARIO OFICIAL 45.444 DECRETO 219 27/01/2004)

En su Artículo $2^{\circ}$ el mismo Decreto establece que el Objeto de La Escuela es "la capacitación, forma- 
ción y desarrollo, desde el contexto de la investigación, docencia y extensión universitaria, de los valores, capacidades y conocimientos de la administración y gestión de lo público que propendan a la transformación del Estado y el ciudadano".

La Estructura Organizacional de la Escuela es definida de la siguiente manera.

- El Consejo Directivo Nacional El Consejo Directivo Nacional está integrado por: a) El Director del Departamento Administrativo de la Función Pública, o su delegado, quien lo presidirá; b) El Ministro de Educación Nacional o su delegado; c) Un miembro designado por el Presidente de la República; d) El Director de Empleo Público del Departamento Administrativo de la Función Pública; e) Un egresado de la Escuela, elegido por los egresados; f) Un Alcalde en representación de la Federación Nacional de Municipios; g) Un Gobernador en representación de la Confederación de Gobernadores; h) Un profesor de la Escuela, elegido por el profesorado; i) Un estudiante regular de la Escuela, elegido por el estudiantado.

Las funciones del Consejo Directivo Nacional son: formular, las políticas académicas y administrativas de la Escuela, los planes y programas conforme a la ley orgánica de planeación y a la ley de presupuesto, proponer los planes sectoriales y su adecuación al Plan Nacional de Desarrollo; formular, la política de mejoramiento continuo de la ESAP; proponer al Gobierno Nacional las modificaciones a la estructura de la Escuela; adoptar el estatuto interno y sus reformas de conformidad con las modificaciones de la estructura; aprobar el anteproyecto de presupuesto anual de la ESAP, autorizar las adiciones y traslados presupuestales que se requieran en el curso de la vigencia; expedir, los reglamentos docente, estudiantil y demás que se requiera para el normal funcionamiento de la Escuela; crear, suspender o suprimir los programas conducentes a título; examinar y aprobar anualmente los estados financieros de la entidad; fijar los derechos pecuniarios de carácter; otorgar los estímulos y las distinciones que determinen los reglamentos; entre otras.

- Consejo Académico Nacional El Consejo Académico Nacional es la máxima autoridad académica de la Escuela. Este está integrado por: a) El Director Nacional, quien lo presidirá; b) El Subdirector Académico, quien lo presidirá en ausencia del Director Nacional; c) El Subdirector de Proyección Institucional; d) El Decano de la Facultad de Investigacio- nes; e) Un representante de los coordinadores académicos de las Direcciones Territoriales; f) Dos representantes de los profesores de carrera docente elegidos por los profesores de carrera, uno por la sede central y otro por las direcciones territoriales; g) Dos estudiantes regulares, uno por la sede nacional y otro por las direcciones territoriales.

Las funciones del Consejo Académico Nacional son definir, establecer y mantener vigentes los propósitos generales de la función académica; crear condiciones para que de manera sistemática, rigurosa y competitiva se desarrollen en la Escuela procesos de construcción, reconstrucción y gestión colectiva del conocimiento en el marco de la administración Pública que permitan dar respuesta efectiva a las demandas de la sociedad y del Estado; impulsar el desarrollo académico de la Escuela; modificar los programas académicos y recomendar al Consejo Directivo Nacional la creación, supresión o fusión de programas de formación, investigación o extensión; emitir concepto previo a la adopción o modificación del estatuto docente y estudiantil y demás disposiciones académicas; rendir informes periódicos al Consejo Directivo Nacional; definir la política en materia de publicaciones académicas institucionales; recomendar los estímulos y distinciones académicas.

- Director Nacional Corresponde al Director Nacional de la ESAP, la representación legal de esta. Es agente del Presidente de la República y de su libre nombramiento y remoción. Las funciones de este son: dirigir, coordinar, vigilar y controlar la ejecución de las funciones y programas propios de la ESAP de su personal; rendir informes generales o periódicos y particulares al Presidente de la República, al Director del Departamento Administrativo de la Función Pública y al Consejo Directivo sobre las actividades desarrolladas y la situación general de la Escuela; presentar al Consejo Directivo Nacional el Plan de Desarrollo de la Escuela, y el presupuesto; presentar al Consejo Directivo Nacional la política de mejoramiento continuo de la ESAP, que garantice su desarrollo académico y administrativo; dirigir, coordinar y vigilar la ejecución del Plan de Desarrollo aprobado por el Consejo Directivo Nacional.

\section{Perspectiva Estratégica}

La Misión Declarada por la Escuela Superior de Administración Pública, ESAP es la siguiente: 


\begin{abstract}
"Formar ciudadanos y ciudadanas en los conocimientos, valores y competencias del saber administrativo público, para el desarrollo de la sociedad, el estado y el fortalecimiento de la capacidad de gestión de las entidades y organizaciones prestadoras de servicio público, en los diferentes niveles de educación superior, educación para el trabajo y el desarrollo humano, la investigación y asistencia técnica en el ámbito territorial, nacional y global"
\end{abstract}

(Plan Decenal de Desarrollo Institucional 2010 2020 ESAP).

La Visión Declarada por la ESAP es ser, en el 2020, una institución de carácter universitario, de calidad académica acreditada, líder en la transformación de la sociedad, las entidades públicas y las organizaciones sociales, órgano consultor del Estado en el saber administrativo público; difundiendo y generando conocimiento en los ámbitos nacional territorial y global.

\section{Perspectiva de la Oferta de Capacitación o Formación}

En la ESAP la oferta de formación o capacitación de está a cargo del Consejo Académico Nacional. En esta Escuela la oferta de formación se clasifica en formación de Pregrado, Postgrado (a cargo de la Subdirección Académica), Educación para el empleo, Desarrollo Humano y capacitación no formal (a cargo de la Subdirección de Alto Gobierno, de la Subdirección de Proyección Institucional).

- La Facultad de Pregrado de la ESAP Se dedica fundamentalmente a desarrollar programas de formación en todas las áreas del conocimiento relacionados con la Administración Pública, abordando también aspectos científicos, investigativos y tecnológicos. La oferta de formación de pregrado está compuesta por los siguientes programas: Administración Pública; Administración Pública Territorial; Tecnología en Gestión Pública Contable; Tecnología en Gestión Pública Financiera; Tecnología en Gestión Pública Ambiental

- Facultad de Postgrado de la ESAP Es facultad se dedica fundamentalmente a la formación avanzada y de profundización de los conocimientos en Administración Pública y del Estado. Abierta a profesionales de diferentes carreras, tiene el objetivo de investigar, reflexionar, estudiar, analizar y resolver problemas nacionales, regionales y locales, dados en el ámbito público. Los programas de postgrado, disponibles también en regiones y sedes de la Escuela dependiendo del programa, son los siguientes: Especialización en Gestión Pública; Especialización en Proyectos de Desarrollo; Especialización en Finanzas Públicas; Especialización en Gerencia Social; Especialización en Gestión Pública; Especialización en Gerencia Hospitalaria; Especialización en Alta Dirección del Estado; Planificación en Desarrollo Urbano y Regional; Especialización en Gerencia Ambiental; Especialización en Fronteras y Relaciones Internacionales; Especialización en Administración Pública Contemporánea.

- Capacitación no formal Dentro de esta oferta de capacitación se encuentran las que desarrolla la Subdirección de Alto Gobierno. Esta Subdirección está encargada de capacitar e impartir inducción a integrantes de la alta gerencia de la Administración Pública, servidores públicos y autoridades electas (Gobernadores, Alcaldes, Diputados, Concejales y Ediles): A fin de fortalecer la dirección estratégica que deberá ejercer el gestor público al interior de las organizaciones.

- Actividades de Formación Complementaria La ESAP, realiza eventos de carácter académico a nivel nacional e internacional como foros, talleres conversatorios, cátedras y seminarios permanentes.

- Determinación de la Oferta En lo que respecta a la determinación de la Oferta de Formación la ESAP, a contar de su proceso de transformación iniciado en el año 2012, la Subdirección General de Capacitación y Competencias Laborales, trabaja en directa cooperación y colaboración con Subdirecciones Territoriales. Estas realizan el análisis, seguimiento, monitoreo y evaluación de la gestión en los organismos o servicios del Estado, lo que les permite diagnósticar las necesidades de capacitación y la preparación de programas de "Educación para el Trabajo y Desarrollo Humano", determinando a su vez técnicas administrativas, buenas prácticas para el trabajo y competencias laborales. De esta forma la ESAP define su demanda y oferta de capacitación extraida directamente desde los organismos, entidades y agencias estatales, servicios públicos y en el marco del sistema de capacitación ya existente en el país.

De esta forma la Escuela ha desarrolado un Modelo de gestión integral, territorial y focalizada que permite efectuar actividades de capacitación bien 
estructuradas enfocada a los diferentes departamentos y municipios, dando respuesta a sus reales demandas de capacitación. Quien integra todas las demandas de capacitación es la Oficina de Articulación Interinstitucional y Regional.

\section{Perspectiva de la Investigación}

La Escuela Superior de Administración Pública ESAP cuenta con una Facultad de Investigaciones, dedicada al desarrollo de la investigación científica, tecnológica y formativa. El objetivo de esta facultad es:

Consolidar grupos de investigación que contribuyan al fortalecimiento de comunidad científica en la ESAP y en el país; Impulsar la producción científico-tecnológica como soporte para el desarrollo de los procesos de docencia y proyección social; Implementar la investigación formativa entendida como fundamento para la consolidación de la disciplina Administración Pública, el estudio del fenómeno de lo público y el desarrollo de los contenidos de los programas de estudio dela ESAP, como condición necesaria para el cumplimiento de los cometidos misionales; Garantizar medios y recursos para los procesos de investigación, privilegiando el trabajo en red, la publicitación y la construcción de públicos para difundir sus resultados; Asegurar en todos los niveles de formación de la ESAP el uso de estrategias pedagógicas creadoras de vocación y experiencia investigativa, con la finalidad de lograr la necesaria articulación entre sus programas y la investigación con criterio interdisciplinario para construir y afianzar la comunidad científica de la ESAP; Realizar investigaciones y estudios de los problemas nacionales de naturaleza administrativa, que permitan el conocimiento de las situaciones que afronta la administración pública en sus distintos niveles y órdenes que sirvan como instrumento para la formulación de políticas públicas.

\section{Perspectiva Redes}

En su Propuesta de Fortalecimiento año 2012 la ESAP se ha propuesto la conformación de redes temáticas que operen en la sede central y en todas las Territoriales. Estas tienen como finalidad, acumular y calificar el conocimiento en un área específica del saber de la Administración Pública.

Por otro lado, a través de la Dirección Nacional de Relaciones Internacionales la Escuela lleva a cabo intercambios académicos con entidades nacionales y extranjeras, con la finalidad de promo- cionar internacionalmente la oferta académica de la ESAP. Entre sus redes cuentan: la Universidad de Antioquia, a fin de desarrollar investigación, intercambio de experiencia, publicaciones entre docentes y estudiantes; el Centro Latinoamericano de Administración para el Desarrollo, CLAD; la Escuela Iberoamericana de Administración y Políticas Públicas; la Asociación Colombiana de Universidades; UNIVERSIA, Red de Universidades, red de oportunidades; el Colegio Colombiano del Administrador Público; la Federación Colombiana de Municipios.

\section{Perspectiva de la Innovación}

En lo que respecta a la Innovación, la Escuela, se encuentra incorporada al Sistema Nacional de Ciencia, Tecnología e Innovación SNCTI. Este es un sistema abierto, tanto las organizaciones públicas, privadas o mixtas que realicen o promuevan el desarrollo de actividades científicas tecnológicas y de innovación. Este sistema está integrado por las políticas, estrategias, programas, metodologías y mecanismos para la gestión, promoción, financiación, protección y divulgación de la investigación científica y la innovación tecnológica en el país.

El SNCTI desarrolla estrategias regionales que tienen como uno de sus fines principales, el apoyo a la gestión pública en los ámbitos regional y local, por medio del fortalecimiento de las entidades territoriales, y de los Consejos Departamentales de Ciencia y Tecnología (Codecyt) como líderes y coordinadores del Sistema. De esta manera, la estrategia apoya la consolidación de los Sistemas Regionales de Ciencia, Tecnología e Innovación.

La estrategia de Regionalización está compuesta del Programa de Planificación Estratégica del Conocimiento (PPEC) en las Regiones; Programa de Fortalecimiento de la Institucionalidad para la Gestión de Conocimiento; Programa de Gestión de Conocimiento y Tecnológica para la Competitividad Regional.

\section{La Academia de Capacitación Muni- cipal y Regional}

\section{Perspectiva Institucional}

La Academia de Capacitación Municipal y Regional es hasta ahora un Departamento de la División de Municipalidades, perteneciente a la Subsecretaría de Desarrollo Regional y Administrativo, del Ministerio del Interior y Seguridad Pública. Surge en el año 2008 como un programa de Estado, 
llamado Sistema Nacional de Capacitación Municipal. Solo a contar del año 2012 recibe el nombre de Academia de Capacitación Municipal y Regional, donde el público objetivo abarca desde entonces, ya no solo a los funcionarios municipales, sino también a los funcionarios de los Gobiernos Regionales.

En lo que respecta al régimen jurídico, que rige el funcionamiento de la Academia, este viene dado por la Ley de Presupuestos dictada cada año para el sector público. Dicha Ley, que para el año 2014 es la Ley $\mathrm{N}^{\circ} 20.713$, le otorga un presupuesto para su gestión de M\$3.252.702.

La Academia tiene como finalidad ser un sistema permanente de capacitación que forme, perfeccione y fortalezca el capital humano municipal y regional, minimizando brechas, certificando competencias, y respondiendo de forma eficiente y oportuna a las necesidades de capacitación de los funcionarios.

El Público Objetivo de la Academia considera a: funcionarios de las municipalidades, gobiernos regionales, e intendencias, contratados bajo las modalidades planta, contrata y para el año 2014, a funcionarios contratados a honorarios; autoridades municipales y regionales; y funcionarios de aquellas Asociaciones de Municipalidades que cuenten con personalidad jurídica.

La Academia en su estructura organizacional está integrada por la Jefatura de Departamento de Academia de Capacitación Municipal y Regional y el Directorio de la Academia. Este último, según se establece en la Ley de Presupuesto del Sector Público, aprueba a inicio de cada año, los lineamientos generales y las políticas de capacitación que orientan la ejecución del presupuesto asignado.

La Jefatura de Departamento Academia de Capacitación Municipal y Regional, tiene a su cargo la Secretaría Ejecutiva de la misma; la dirección del funcionamiento de la Academia; la coordinación con autoridades de gobierno, ministeriales, regionales y locales para la ejecución de las actividades que desarrolla; diagnóstico de las necesidades de capacitación de los funcionarios de gobiernos regionales y municipales, así como el diseño, ejecución y evaluación de cada línea de formación y capacitación que responda a dichas necesidades; gestión de los recursos financieros y personal bajo su responsabilidad, dando cumplimiento a los objetivos del área de desempeño (Departamento) y de la institución (SUBDERE); desempeñar otras funciones relacionadas a las temáticas del área de desempeño encomendadas por la jefatura.

Son jefaturas y autoridades con poder de decisión sobre la Academia, en primer lugar el Subsecretario de Desarrollo Regional y el Jefe de División de
Municipalidades. A estos la Jefa de la Academia le debe subordinación y obediencia en la ejecución de las políticas de capacitación.

\section{Perspectiva Estratégica}

- Misión Contribuir a la modernización y desarrollo de los gobiernos locales y regionales siendo facilitador de la gestión de capacitación para funcionarios y autoridades, a fin de hacer más eficiente y eficaz el servicio prestado a la comunidad.

- Visión Ser el organismo que contribuya a la capacitación y certificación de los funcionarios y autoridades de los gobiernos locales y regionales de manera masiva, a través del uso de la tecnología, asegurando pertinencia, oportunidad e impacto en la gestión local y gubernamental.

- Objetivos La Academia de Capacitación Municipal y Regional tiene como objetivo principal promover la capacitación continua como pilar fundamental en la gestión de las administraciones subnacionales, sean estas municipalidades y gobiernos regionales focalizada en autoridades y funcionarios, a través de un programa anual de capacitación, de manera de generar iniciativas de capacitación para el público definido como objetivo, que permitan perfeccionar el desarrollo del capital humano local.

\section{Perspectiva de la Oferta de Capacitación o Formación}

En lo que respecta a la determinación de la oferta de capacitación, la Academia se basa fundamentalmente en estudios de diagnóstico de necesidades de capacitación que contrata, a través procesos de licitación pública, conforme a lo estipulado en la Ley $\mathrm{N}^{\circ} 19.886$ Ley de Compras Públicas. Por otro lado, toda vez que la Academia lleva a cabo una capacitación, en cualquiera de sus modalidades, aplica encuestas de satisfacción, oportunidad que aprovecha también, para consultar a los funcionarios respecto de sus necesidades de capacitación. Otra forma de determinar la oferta de capacitación es con reuniones y trabajos en terreno, entrevistando o desarrollando "focus group" con alcaldes, concejales y funcionarios.

La oferta de capacitación de la Academia, se clasifica en: Capacitación Directiva, Capacitación por Competencias, Capacitación Contingente y Capacitación con Alianzas Estratégicas. 
- Capacitación Directiva Corresponde a programas de formación denominados Diplomados. Están enfocados principalmente a directivos y profesionales que deseen alcanzar mayor especialización en determinadas materias, a fin de contribuir de mejor forma en las municipalidades o gobiernos regionales donde se desempeñan.

- Capacitación por Competencias Es un sistema de capacitación dirigido a funcionarios municipales, que busca garantizar, en virtud de un levantamiento previo de perfiles ocupacionales, un nivel estándar de conocimientos y competencias. Dicho sistema se inicia en el nivel básico (Gestor General), para luego continuar con un nivel intermedio (Gestor Intermedio) y finalmente un nivel de especialización (Gestor Específico).

- Capacitación Contingente Son capacitaciones que lleva a cabo la Academia, con el fin de satisfacer necesidades de capacitación en temas específicos, derivados de la contingencia que atañe directamente a la gestión municipal y regional. De esta forma, se busca dotar a los servidores públicos, de herramientas e información actualizada, para dar respuestas prontas y oportunas a las demandas que se hacen desde la ciudadanía y desde el nivel central. Dichas capacitaciones están orientadas a todo el personal municipal y regional, cuenta con una duración entre 8 y 50 horas pedagógicas, dictados bajo la modalidad presencial, y son impartidos por especialistas en las respectivas temáticas.

- Capacitación en Alianzas Estratégicas Son Programas de Capacitación que desarrolla la Academia en Alianza Estratégica con otros servicios públicos, considerados de alto nivel técnico, en temas que agregarán valor al servicio que la municipalidad o gobierno regional presta a la comunidad.

El modelo de negocio adoptado por la Academia para llegar con sus programas de formación y capacitación a los funcionarios municipales y regionales, considera la licitación pública de todos los cursos y capacitaciones que lleva a cabo, contratando de esta forma a universidades o centros de formación, acreditados, para que sean estos quienes ejecuten finalmente la respectiva capacitación. De esta forma, como se puede observar, la Academia no cuenta con un espacio o infraestructura física para el desarrollo de su gestión, esto dado a que desde su origen como Sistema Nacional de Capacitación Municipal, nunca fue pensado y asociado, en el desarrollo de sus funciones, a un lugar físico ni estructura tradicional de Escuela o Universidad. Sino más bien, se consideró que su despliegue y gestión, sería a través una plataforma virtual y staff de profesionales para desarrollar funciones de dirección, coordinación, control, y evaluación, de las capacitaciones contratadas. A esto además, el staff de profesionales con que cuenta la Academia, se dedican a la elaboración de bases de licitación, publicar los llamados de licitación, hacer evaluación de las ofertas presentadas por la distintas universidades, efectuar las adjudicaciones y contrataciones respectivas, y realizar toda la gestión de pagos asociada a cada contratación de capacitación o programa de formación, hacen seguimiento y cierre de cada proyecto de capacitación.

\section{Perspectiva docente y métodos de enseñanza}

En lo que respecta a los docentes y métodos de enseñanza, estos quedan supeditados a lo establecido en las bases de licitación y a la oferta que la respectiva universidad haga a la Academia. En General las Estrategias formativas consensuadas entre la Academia y la Universidad contratada consideran: clases de docencia impartidas por expertos; resolución de casos; talleres de aplicación práctica; lectura de material bibliográfico; trabajo a desarrollar por el estudiante en su localidad o lugar de trabajo; uso de plataforma B-Learning.

\section{Perspectiva de la Investigación}

En general la Academia no desarrolla investigaciones, estudios o líneas investigativas, no cuenta en su estructura organizacional con un área con dedicación a esta función.

\section{Perspectiva de redes}

La Academia solo trabaja en conjunto con aquellos servicios públicos chilenos con los cuales lleva a cabo capacitaciones específicas; y con aquellas universidades o centros de formación con los cuales contrata para la ejecución de los programas de capacitación licitado. En general, no se ha preocupado de desarrollar redes institucionales, ya sea con otras Academia o Institutos de formación en áreas de la Administración Pública, o con otras instancias que le permitan intercambiar experiencia conocimiento y buenas prácticas.

\section{Perspectiva de la Innovación}

La Academia no cuenta en su estructura y funciones con un área o personal dedicado al desarrollo de la Innovación ya sea en la gestión y prácticas del 
quehacer municipal y regional, o en materias de formación de funcionarios públicos en general o local en particular.

\section{Aprendizajes y recomendacio- nes para la Academia de Capa- citación Municipal y Regional}

\section{Perspectiva Institucional}

La Academia debe contar con una Institucionalidad y Estructura Organizacional ad hoc a las altas tareas que se le han encomendado. Al respecto, cabe señalar que hasta diciembre de 2013, la Academia, dentro de la estructura organizacional de la Subsecretaría de Desarrollo Regional y Administrativo (SUBDERE), era solo una Unidad dependiente del Departamento de Desarrollo Municipal, el cual a su vez está inserto dentro de la División de Municipalidades de SUBDERE. Sólo a contar de enero de 2014 la Academia pasó a ser un Departamento, por sí sola, siguiendo, eso sí, bajo la dependencia de la División de Municipalidades de dicha Subsecretaría.

Esto implica, por un lado, que el Directorio, que tiene como finalidad aprobar las líneas de acción que la Academia ha presupuestado desarrollar para el año respectivo, sea solo una formalidad, ya que quienes definitivamente, aprueban las líneas programadas y desarrolladas por la Academia, son en una primera instancia la jefatura de División de Municipalidades, el Subsecretario de Desarrollo Regional y Administrativo, e incluso el Ministro del Interior y Seguridad Pública; y en una segunda instancia la Dirección de Presupuestos DIPRES del Ministerio de Hacienda, una vez aprobada la formulación presupuestaria del año siguiente. De esta forma, esta situación, de total dependencia y nula autonomía académica, administrativa y financiera, ha atentado directamente en contra de la eficiencia y eficacia de los procesos formativos y de capacitación.

La propuesta del presente estudio de caso, va en esa misma dirección y plantea que el Reglamento señalado en el artículo 8 del proyecto, sea una oportunidad para dar la configuración institucional y organizacional que la Academia necesita para convertirse en la práctica un organismo público dedicado a la formación y perfeccionamiento de funcionarios municipales, así como también a generar conocimiento a través de la investigación, estudios y publicación de la Administración y función pública local. Contando con mayor autonomía académica, de gestión y financiera para el logro de su misión.
En lo que respecta a la estructura organizacional, el proyecto de ley, como se señaló anteriormente, establece que el Fondo dependerá de la Subsecretaría de Desarrollo Regional y Administrativo. Sin embargo, la Administración de dicho Fondo queda radicada en el Directorio de la Academia de Capacitación Municipal y Regional. Por lo tanto, a contar de la promulgación y publicación de la Ley, el Directorio contará con las atribuciones legales que le permitan jugar un rol preponderante y ya no solo formal, como lo ha sido hasta ahora.

La propuesta del presente estudio recomienda que sea fundamental definir en el reglamento lo que se entiende por Administración del Fondo. La definición propuesta por el presente estudio va en la línea de la figura del Consejo de Administración de la Escuela Nacional de Administración de Francia ENA. Es decir, que el Directorio sea para la Academia de Capacitación Municipal y Regional lo que el Consejo de Administración es para la Escuela Nacional de Administración de Francia ENA. Por lo tanto, la definición de: Administración del Fondo, debe ir explícitamente en el Reglamento, de modo de no tener en la gestión futura de la Academia de Capacitación Municipal y Regional, intromisión de un ente como el actual Directorio de la Academia en funciones que son propias de otro ente de carácter más bien gerencial y de gestión.

Por lo tanto, para el Reglamento se debería entender por Administración del Fondo que compete al Directorio, las funciones de: ser consultado sobre el funcionamiento general, los medios y recursos financieros utilizados; aprobar los llamados a concurso y áreas de estudio financiables; aprobar las acciones que se financiarán con el Fondo; aprobar las condiciones de acceso a los regímenes de formación de la Academia.

En lo que respecta a los miembros que deberían integrar este Directorio, se considera que este cuente al menos con: actores relevantes del áreas municipal (como lo es actualmente) y también actores relevantes o personalidades elegidas en razón de sus competencias, no solo por el cargo que ostentan sino que también, por su expetis en el ámbito académico; en la función pública local; y en el desarrollo del capital humano calificado.

Por otra parte, el reglamento debería considerar a la Dirección. Esta radicaría en la Jefatura de lo que es actualmente el Departamento Academia de Capacitación Municipal y Regional.

Por otro lado, la estructura organizacional debe considerar al menos de cuatro subdirecciones importantes, como lo son: 
- Subdirección Académica, que estará compuesta por:

- Área de Pregrado

- Área de formación técnica

- Área de Diplomados y Postítulo.

- Subdirección de Investigación e Innovación.

- Subdirección de Redes y Alianzas Estratégicas.

- Subdirección de Gestión.

La propuesta del presente estudio de caso, es que el reglamento suprima el requisito administrativo de contar con Decreto Exento del Ministro del Interior y Seguridad Pública para la total tramitación de la contratación de un programa de formación. Es decir, que para la contratación de una universidad o instituto, según sea el caso, baste con la dictación de una resolución del Subsecretario de Desarrollo Regional y Administrativo, para que esta sea efectiva. Con el solo hecho de quitar el trámite de firma del Ministro de Interior y Seguridad Pública, el proceso licitatorio se acortaría en al menos 3 meses de las 6 que dura en la actualidad.

\section{Perspectiva Estratégica}

Como se puede apreciar, el proyecto de ley recién aprobado, al crear del Fondo Concursable de Formación de Funcionarios Municipales, viene restructurar y cambiar el modo de operar, hasta ahora conocido de la Academia de Capacitación Municipal y Regional; ampliar su ámbito de acción y su oferta de formación y capacitación. Por lo tanto su Misión, Visión y Objetivos Estratégicos deben también ser modificados.

\section{Perspectiva de la Oferta de Capacita- ción o Formación}

Una vez promulgada y publicada la Ley, del proyecto de ley del Boletín 8210-06, la Academia deberá incorporar, tal y como lo señala el Artículo $4^{\circ}$, formación que permita la obtención de Título profesional; Título técnico; Diplomado o postítulo.

El presente estudio propone que la oferta de capacitación se defina en virtud de los planes anuales presentados por las municipalidades a sus respectivos concejos. Para esto es fundamental, que una vez promulgada y publicada la Ley:
1. Exista un período de capacitación y acompañamiento que permita dejar capacidad instalada en todos los municipios del país, no solo en el cumplimiento de la Ley, sino también en la calidad técnica de los planes anuales que se levanten. Los cuales deben responder a las brechas detectadas en virtud de los perfiles ocupacionales acreditados.

2. Establecer en el reglamento del Fondo Concursable de Formación de Funcionarios Municipales, que la formación recibida por el funcionario esté directamente vinculada con el ascenso y desarrollo de la carrera funcionaria. De esta forma, el funcionario por el cual una municipalidad solicite formación o capacitación, debe por un lado retribuir en el mismo municipio, por un período de tiempo determinado la formación adquirida, pero también ser la primera opción municipal al momento de efectuar la promoción interna, ascenso, aumento de grado.

3. El Plan Anual Municipal debe estar conformado por el conjunto de Planes Personalizados de Desarrollo Profesional y Humano de cada funcionario. Por lo tanto, la municipalidad, a través de su Departamento de Recursos Humanos, debe velar porque cada funcionario cuente con un Plan Personalizado de Desarrollo Profesional y Humano. La municipalidad debe seguir los siguientes pasos: a) definir el perfil de cargo necesario para cumplir sus objetivos; b) contrastar el perfil del cargo levantado con el perfil del profesional o funcionario que ocupa el cargo; c) considerar la evaluación de la jefatura directa del funcionario; y d) considerar la autoevaluación que el propio funcionario realice de su desempeño en el cargo. Considerando y ponderando esos cuatro elementos, la municipalidad debe generar el Plan Personalizado de Desarrollo Profesional y Humano. Finalmente el Plan Anual resultante debe ser presentado al concejo y posteriormente a la Academia de Capacitación Municipal, para efectos de solicitar becas para la formación y capacitación de sus funcionarios, con cargo a los recursos del Fondo Concursable de Formación de Funcionarios Municipales.

\section{Perspectivas docentes y métodos de enseñanza}

La Academia debe velar por que tanto los docentes sean expertos con experiencia en el trabajo municipal; y que los métodos de enseñanza sean totalmente aplicables al ámbito de las municipalidades. En este sentido, es importante generar bases de licitación y posteriores contratos con las universidades 
e institutos que garanticen por un lado la calidad, expetis, experiencia docente y métodos de enseñanza. No obstante, también es necesario que las bases de licitación dejen el espacio suficiente para que las entidades académicas presenten ofertas competitivas y de alta calidad, evitando de esta manera que las ofertas presentadas por las universidades o institutos, sean fiel copia de las bases de licitación. Esto obliga a las comisiones evaluadoras a seleccionar la oferta más económica, toda vez que las ofertas técnicas presentadas no presenten diferencias relevantes entre sí.

Es importante, también a la luz de los casos internacionales analizados, que las instancias formativas, consideren prácticas en terreno; pasantías de funcionarios de municipalidades con menores niveles de gestión en municipalidades superiores, a fin de que puedan apreciar en la práctica la forma de trabajo y de gestión que les permita mejorar sus competencias.

Por otro lado, la Academia debe contar con una base de datos, que contenga las coordenadas de aquellos funcionarios municipales expertos en sus áreas de trabajo, y que estén disponibles para ejercer como mentores de funcionarios municipales de otros municipios. En este sentido, se propone contar con mentores en los perfiles ocupacionales ya levantados, los cuales deben recibir la certificación respectiva en dichos perfiles. Por su parte, se propone que los funcionarios alumnos reciban el adiestramiento tanto en el lugar de trabajo del mentor, como en el lugar de trabajo del propio alumno. El trabajo del mentor debe también ser remunerado y generar los incentivos para que este cuente con la motivación necesaria en el desarrollo de su rol.

\section{Perspectiva de la Investigación e In- novación}

La Subdirección de Investigación e Innovación debe orientar el trabajo y gestión de la Academia de Capacitación Municipal y Regional, permitiendo que al momento de preparar bases de licitación y llevar a cabo procesos de contratación de programas de formación, sea un cliente altamente informado y esté en condiciones de exigir un servicio de alto nivel por parte de las universidades o institutos que participen de los procesos de licitación y contratación, toda vez que serán financiados con recursos públicos. Para que de esta forma, los profesionales con los que cuente la Academia en el desarrollo de estas funciones, estén en pie de negociar y pactar en igualdad de condiciones con las universidades e institutos oferentes o contratados, un buen estándar de servicio en pos del funcionario municipal que re- cibirá la capacitación y también por la inversión eficiente y eficaz de los recursos del Estado.

Por otra parte, esta subdirección permitirá ser una fuente o centro de documentación de la producción académica que se genera cada vez que se dicta un curso o programa de formación. Cabe señalar, que los materiales académicos generados de los cursos, no son recopilados, almacenados, catalogados ni puestos a disposición de quienes quieran o deseen consultarlos. Estos son un elemento fundamental y de gran valor, donde en la mayor parte de los casos se ponen a libre disposición en sus bibliotecas tanto físicas como virtuales, a fin de que todos tengan libre acceso al conocimiento generado.

A su vez esta subdirección tendrá la responsabilidad de analizar los estudios que otras escuelas de administración y formación de funcionarios públicos en general y funcionarios locales en particular, generan. Dado los casos analizados del ámbito internacional, se puede observar, que existe mucha información disponible que puede agregar valor al trabajo que desarrolla la Academia formando a funcionarios municipales.

Por otro lado, existe mucha experiencia internacional en este sentido, que puede ser bien aprovechada. Este estudio de caso propone que la Academia de Capacitación considere dentro de la subdirección de investigación e innovación las siguientes líneas de trabajo:

- La convocatoria permanente para la contratación de proyectos de investigación. Muy en la línea del modelo de negocio de la Academia, tendiente a externalizar todos los servicios que presta.

- Desarrollo de Redes de investigación e innovación.

- Observatorio de Buenas Prácticas e Innovadoras en gobiernos locales tanto nacionales como internacionales.

- Premios y reconocimientos para aquellos alumnos que cursando alguno de los programas de formación de la Academia, desarrollen trabajos de investigación, estudios de caso o trabajos que signifiquen generar conocimiento y agregación de valor a la función pública municipal, al fortalecimiento del capital humano municipal o al desarrollo económico local; así como también para aquellas propuestas presentadas por los alumnos que signifiquen innovación para el desarrollo de la gestión local.

- Contar con una Biblioteca con espacio físico y virtual que permita ir coleccionando los estudios, trabajos e investigaciones que se generan 
en el cumplimiento de la Misión de la Academia, así como todo el material bibliográfico y documental especializado en las materias propias de las competencias de la Academia de Capacitación Municipal y Regional.

- Generar eventos, foros y jornadas destinados a debatir y generar conocimiento sobre temáticas de la contingencia, en materias propias y atingentes al ámbito de acción de la Academia.

\section{Perspectiva de Redes}

El presente estudio propone que la generación de redes debe iniciarse desde el interior mismo de la Subsecretaría de Desarrollo Regional y Administrativo. Donde la Academia debe comprometerse a actuar coordinadamente con el trabajo de las otras divisiones, departamentos y programas que coexisten dentro de la SUBDERE, aprovechando las sinergias que se pueden generar a interior de esta.

En este sentido, un ejemplo claro de alianza coordinada es la que se desarrolla con la División de Políticas y Estudios, la cual está en constante producción de conocimiento respecto de la realidad local, la función pública, estudios de diagnóstico y caracterización de los funcionarios municipales, que serán un insumo fundamental para el trabajo de la Academia.

Por otro lado, es imprescindible que la Academia genere alianzas con:

- Los principales agentes de formación de funcionarios tanto nacional como internacional, y con organismos internacionales de administración pública como el CLAD, BID, Banco Mundial, a fin de sacar lecciones y aprendizajes, para de esta forma apuntar a la excelencia y mejora continua.

- Las Municipalidades, Gobiernos Regionales y las respectivas Asociaciones, a fin de actuar coordinadamente en la formulación de programas de formación y capacitación de los funcionarios.

- Dado el nuevo rol que tendrá la Academia una vez promulgada y publicada la Ley del proyecto que consta en el Boletín № 8210-06, fundamental será generar redes y alianzas con otros servicios públicos como lo son el Servicio Civil dada su especialidad en la gestión de personas (sobre todo en lo que se refiere al desarrollo) donde la formación y capacitación es neurálgica; así como con la Comisión Nacional de Investigación Científica y Tecnológica
(CONICYT) sobre todo en lo que respecta a la gestión de selección de programas formativos y gestión y acompañamiento al becario.

- Se propone también generar una red de Directivos Públicos Locales.

- Se propone finalmente la concreción de una red de funcionarios mentores certificados en perfiles específicos de la gestión local.

\section{Conclusiones}

Dando respuesta a la pregunta de investigación que orientó el presente estudio de caso, se puede señalar que la Academia de Capacitación Municipal y Regional, tiene un rol preponderante, como aliada estratégica de los municipios del país, en desarrollar el capital humano calificado de los funcionarios municipales.

Para esto cuenta, por un lado, con una amplia experiencia y camino recorrido por otros organismos públicos, tanto nacionales como internacionales, de distintos países, de los cuales adquirir experiencia y aprendizajes.

Por otro lado, la Academia se encuentra en un momento histórico de su existencia, ya que la publicación de la Ley del Boletín № 8210-06 que crea el "Fondo Concursable de Formación de Funcionarios Municipales" representa una clara señal del interés que tienen, tanto el ejecutivo como el legislativo, de desarrollar el capital humano calificado del sector municipal. La Academia cuenta entonces, con la oportunidad cierta de alcanzar la institucionalidad, autonomía, estructura organizacional y recursos para convertirse en la institución líder y centro altamente especializado en formación, capacitación y generación de conocimiento en pos del desarrollo del capital humano calificado municipal y la gestión pública local.

Producto de dicha oportunidad, tiene la obligación de convertirse en la institucionalidad pública que articule esfuerzos, recursos, actores y voluntades, a fin de que la formación y capacitación entregada este asociada al ascenso, aumento de grados y que los funcionarios que esta forme y capacite sean prioridad para el reclutamiento y selección de personas en cargos disponibles en las municipalidades que ingresen al sistema. Dando cuenta, con dicha institucionalidad, de manera concreta, del desarrollo de una carrera funcionaria de las personas que trabajan en los municipios del país. Tal como ocurre con las escuelas internacionales estudiadas en el presente estudio de caso. 
Lo anterior, sin duda es relevante no solo desde el punto de vista del aumento en el valor público que con ello pueda generar la Academia, logrando un mejoramiento en las prácticas de gestión (en el corto plazo) y desarrollo de carrera funcionaria; sino que también, en el largo plazo, un aumento del bienestar del ciudadano usuario de los servicios que la municipalidad otorga a la comunidad.

\section{Referencias}

Abarzúa, E. (2012). Modelo de Gestión de Personas para la Administración Central del Estado. Technical report, Santiago.

Accioneli, E., Brida, J., y London, S. (2007). Crecimiento económico y trampas de pobreza: Â¿cuál es el papel del capital humano? Revista Investigación Económica, LXVI(261):97-118.

Asociación Chilena de Municipalidades (2006). Deterioro del Financiamiento Municipal. Santiago de Chile.

Barro, R. y Sala-i Martin, X. (1995). Technological Diffusion, Convergence and Growth. Papers, (735).

Bonardo, D. (2009). Los Recursos Humanos en el
Ámbito Municipal y el Desarrollo Local. Revista Pilquen, XI(11):1-7.

Giménez, G. (2005). La dotación de Capital humano en América Latina y el Caribe. Revista de la CEPAL, (86):103-112.

Helpman, E. y Grossman, G. (1993). Innovation and growth in the global economy. MIT Press, Cambridge, Massachusetts.

Horst, B. (2009). Fuentes de financiamiento para gobiernos subnacionales y descentralización fiscal. Libertad y Desarrollo, Santiago.

Keeley, B. (2007). Capital Humano Cómo influye en su vida lo que usted sabe, Percepciones de la OCDE. Ediciones Castillo, Paris.

Lloyd-Ellis, H. y Roberts, J. (2000). Twin Engines of Growth. Working Papers.

Ormeño, H. (2011). Una aproximación empírica al Capital Humano Municipal en Chile. Revista Chilena de Administración Pública, (17):109136.

Waissbluth, M. (2006). De la Confrontación al Consenso: La Reforma del Estado en Chile 1990-2005. Public. 